\title{
41. Making the case for agroecological innovation: the need for technical but also political entrepreneurs
}

Sébastien Treyer

In many regions around the world, local farmers supported by their producers' organizations, international non-governmental organizations (NGOs) and local and international researchers have been able to demonstrate, at the scale of their territory, the performance of agroecological innovation to jointly reach economic, social and environmental objectives. Instead of relying on ever greater use of chemical inputs (pesticides, fertilizers), agroecological innovation - that is, not about keeping traditional farming systems in a state of low productivity, as is often pretended - aims at changing the whole system of practices by using more ecological knowledge of the functioning of agroecosystems: it thus enables the mobilization and optimization of natural cycles in the ecosystems in order to maximize expected benefits: improved income for the farmers, enhanced resilience in the face of economic and climatic shocks, and better environmental quality (biodiversity, carbon storage in soils, reduced pollution of water and air).

Examples are numerous. Integrated pest management, relying on predators and changes in the agricultural landscape to control pests, rather than using pesticides. Or the constitution of a complex agricultural landscape with different layers of vegetation, associated on the same plot, or in a complex pluriannual crop sequence, optimizing the synergies: for instance, nitrogen-fixating legumes that provide nitrogen to the associated cereals, instead of specialized fields of monoculture that seek to avoid any competition with other plants, but increases vulnerability to invasions by pests and weeds. Overall, integrating ecology into agronomy is a very knowledge-intensive innovation pathway, and could be accelerated by recent advances in information technology and big data, as well as in ecology or even metagenomics: understanding the genetic diversity across a whole ecosystem could be very useful to better understand and optimize its functioning.

This is particularly true in arid and semi-arid areas, where the protection against soil degradation is vital, and where the recomplexification of the agri- 
cultural landscape is absolutely crucial to maintaining organic matter in soils, thus better retaining water for the plants in the agroecosystem. Although such cases are numerous and well documented, their economic performance is often questioned when discussing national agricultural policies: yields of individual crops might indeed be lower in an agroecological system than in a high-input intensified one, whereas if you count all the different types of vegetal production associated on the same plot, the overall yield of the agroecological system might actually be higher. When considering future scenarios for farm development in a tropical context in Africa that would be characterized both by a low level of input use and a low level of productivity, decision-makers from national governments as well as from development partners are prone to consider only one scenario: specialization in one type of crop, with the example of Southern American monocultures in mind, looking for high yields through intensification in inputs and technical capital. But other scenarios are possible, inspired instead by Central American or Southeast Asian agroforests, very complex systems that are less input intensive and more labour and knowledge intensive, and able to reach very high levels of productivity.

But political decision-makers and development planners are focusing mainly on one indicator to assess economic profitability and return on investment: yields of a dominant crop, as if monoculture was the only model, and yields taken as a proxy for livelihood, well-being and food security of the farmers, which is very questionable. We need to understand that this lens is too narrow with which to assess even the economic profitability dimension of agricultural development, as it does not account for the other crops in a complex despecialized farming landscape, even less as an assessment of the value and real economic profit of the whole system, or its resilience, if input charges are reduced and if diversification is used as a risk reduction strategy. But to properly assess the performances of such systems on the relevant variety of indicators, what is needed is local and site-specific knowledge, which seems much more complicated to collect and compile than statistics on yields for one crop. On top of the usual and common imbalance between new entrants and incumbents, this complexity in technical and economic assessment contributes to explaining the asymmetry of political weight in major policy decisions respectively of agroecological options and models and of business as usual scenarios - that is, input-intensive green revolution packages.

For arid regions, a network of NGOs, the Centre d'Actions et de Réalisations Internationales (CARI), particularly originating from projects in the Sahel region of Africa, has designed and implemented a scientific and political strategy to redress this imbalance. They are busy gathering, harmonizing scientific and grassroots data on the performance of agroecological innovations across different countries and regions, making them scientifically robust by also assessing their limits, and promoting them through a dedicated 
advocacy strategy at subnational, national, regional as well as global scales (United Nations Framework Convention on Climate Change, United Nations Convention to Combat Desertification fora, for instance). Former Food and Agriculture Organization director-general Graziano da Silva acknowledged that agroecology is a crucial innovation option for our future, in order to attain food security, prosperity and sustainability. Political entrepreneurship proves critical at all these scales.

In Bolivia, former president Evo Morales had taken the political position not to choose between agriculture industrialization and specialization, occurring mostly in the lowlands, and support for complex agroecological farming systems, mostly in the Andean part of the country, where another network of NGOs called the Centro de Investigación y Promoción del Campesinado (CIPCA) is very active. This ends up in a competition between the two types of strategies of transformation for the agricultural sector, for resources like land and water, market access, as well as for political attention. In such a situation, federative organization, coalition building and sense of political strategy are at the heart of the ability for entrepreneurs to develop if they want to contribute to the transformation towards sustainability, on top of being able to mobilize research to demonstrate the technical performance of an alternative pathway for agricultural systems.

In such a tense strategic context, where asymmetry in political weight, in access to financial but also scientific resources, linking innovative groups of farmers with groups of consumers that are looking for a new role in the food system appears to be a particularly promising political strategy. Slow Food, an international network able to attract a lot of media and political attention, linking consumers and producers locally and globally, has developed Terra Madre, a network of farmers' projects enabling them to attract funding for their agroecological innovations, as well as cities developing innovative food policies. Such strategic coalitions are necessary to open up the political space for agroecological innovation pathways. 